ISSN 0258-7122

Bangladesh J. Agril. Res. 38(4): 647-657, December 2013

\title{
VARIABILITY AND HERITABILITY ANALYSIS IN SHORT DURATION AND HIGH YIELDING Brassica rapa L.
}

\author{
M. H. KHAN ${ }^{1}$, S. R. BHUIYAN ${ }^{2}$, M. H. RASHID ${ }^{3}$ \\ S. GHOSH ${ }^{4}$ AND S. K. PAUL ${ }^{5}$
}

\begin{abstract}
The experiment was carried out with 32 genotypes of Brassica rapa including two commercially cultivated varieties as checks to study their inter-genotypic variability, heritability, GCV, PCV, genetic advance, and CV percent considering 10 morphological characters at the experimental farm of SAU, Dhaka during November 2009 to February 2010. Significant variation was observed among the genotypes for all the characters studied except thousand seed weight. High GCV and PCV values were observed for number of secondary branches/plant. High heritability values along with low genetic advance in percentage of mean were obtained for 1000 -seed weight, number of secondary branches/plant, seeds/siliquae, and siliquae length. Highly significant positive association of seed yield per plant was observed with number of primary branches/plant, number of secondary branches/plant and number of siliquae/plant. Considering variability among the genotypes, heritability, genetic advance, percent co-efficient of variance, and field performances, the genotypes G-15, G-19, G-1, G-3, G-4, G-10, G-18, G21, and G-24 were found suitable for future breeding programme.
\end{abstract}

Keywords: Variability, heritability, Brassica rapa L.

\section{Introduction}

Rapeseed-mustard is a major oilseed crop in Bangladesh. It contributes a lion share to the total edible oil production of the country. Most of the developed varieties take long duration to mature except a few. As a result, they do not fit well in the existing T.aman - Mustard - Boro cropping pattern. Brassica have great economic and commercial value and play a major role in our daily diet. Fat and oil are vital components of the human diet because they are important sources of energy and act as a carrier of fat soluble vitamins. Poor intake of fat and oil reduce the availability of fat soluble vitamins and cause dietary imbalance and food wastage. In a balanced diet, $20-25 \%$ of calories should come from fats and oils and the average need of fats and oils is about $37 \mathrm{~g} /$ day (Rahman, 1981). The seeds of Brassica rapa contain $42 \%$ oil and 25\% protein (Khaleque, 1985). There is limited scope of horizontal expansion of cultivation of mustard. So, for increasing mustard production, yield must be increased per unit area. High

${ }^{1,4 \& 5}$ Scientific Officer and ${ }^{3}$ Senior Scientific Officer, Bangladesh Agricultural Research Institute (BARI), ${ }^{2}$ Professor, Dept. of Genetics \& Plant Breeding, Sher-e-Bangla Agricultural University (SAU), Dhaka, Bangladesh. 
yielding and short duration rapeseed mustard varieties should be developed to fit into the existing cropping pattern. Thus $\mathrm{F}_{7}$ generations have been generated through different inter varietals crosses of Brassica juncea. The present study was conducted to find out the variability, character association and the direct and indirect effects of different characters on yield per plant which will give an opportunity to select the desired plant types to meet the existing demand. Information on genetic variability is necessary for initiating a successful breeding programme (Behl et al., 1992). Genetic variability is a prerequisite for a successful breeding programme of any crop species and a critical survey of genetic variability is essential before initiating an improvement programme aiming to develop high yielding varieties (Falconer, 1989). The genetic variability in a population along with heritability gives an idea of genetic advance to be expected from selection for a given character (Burton, 1952; Johanson et al., 1955).

\section{Materials and Method}

The present experiment was conducted at the experimental farm of Sher-eBangla Agricultural University (SAU), Dhaka-1207 during November 2009 to February 2010. A total number of 32 materials were used in this experiment where two were parents and 30 were $F_{7}$ segregating lines (Table 2). The crop was fertilized at the rate of 10 tons of cowdung, $250 \mathrm{~kg}$ urea, $175 \mathrm{~kg}$ triple super phosphate (TSP), $85 \mathrm{~kg}$ muriate of potash (MoP), $250 \mathrm{~kg}$ gypsum, $3 \mathrm{~kg}$ zinc oxide, and $1 \mathrm{~kg}$ boron per hectare. The half amount of urea and total amount of cowdung, TSP, MoP, gypsum, zinc oxide, and Boron were applied during final land preparation. The rest amount of urea was applied as top dressing after 25 days of sowing. The experiment was laid out in randomized complete block design (RCBD) with three replications. The total area of the experiment was $37 \mathrm{~m}$ $\times 11 \mathrm{~m}=407 \mathrm{~m}^{2}$. Each replication size was $37 \mathrm{~m} \times 2.7 \mathrm{~m}$ and the distance between replication to replication was $1 \mathrm{~m}$. The spacing between line to line was $30 \mathrm{~cm}$. Seeds were sown in lines in the experimental plots on 4 November 2009. The seeds were placed at about $1.5 \mathrm{~cm}$ depth in the soil. Intercultural operations, such as weeding, thinning, irrigation, pest management, etc. were done uniformly in all the plots as and when necessary. Aphid infection was found in the crop during the siliquae development stage. To control aphids, Malathion-57 EC @ $2 \mathrm{ml} /$ liter of water was applied. Harvesting was done from $4^{\text {th }}$ to $15^{\text {th }}$ February 2010 depending upon the maturity of the genotypes.

For studying different genetic parameters and inter-relationships, 10 characters were taken into consideration. The data were recorded on randomly 10 selected plants for each of the parental lines and $\mathrm{F}_{8}$ progenies on the following traits- days to $50 \%$ flowering, days to $80 \%$ maturity, plant height $(\mathrm{cm})$, number of primary branches/plant, number of secondary branches/plant, number of 
siliquae/plant, siliquae length (cm), number of seeds/siliquae, 1000-seed weight (g), and seed yield/plant (g). The data were analyzed for phenotypic and genotypic variances Johnson et al. (1955). Heritability and genetic advance were measured using the formulae given by Singh and Chaudhary (1985) and Allard (1960). Genetic advance in percentage of mean were calculated as suggested by Johnson et al. (1955).

\section{Results and Discussion}

The mean, range, and CV (\%) of seed yield and yield contributing characters of 32 genotypes of Brassica rapa along with checks are presented in Table 1. Variations were observed among the lines for all the characters studied. Days to $50 \%$ flowering ranged from 30.33 to 36.00 . Genotype G17 and G19 showed the lowest days to flowering, the highest was in genotype G1. Plant height ranged from 74.33 to $118.33 \mathrm{~cm}$. Genotype G19 showed the highest $(118.33 \mathrm{~cm})$ and genotype G23 was the lowest in $(74.33 \mathrm{~cm})$ plant height. Number of primary branches/plant ranged from 4.20 to 9.40 . Genotype G10 and genotype G23 showed the highest (9.40) and the lowest (4.20) number of primary branches/plant, respectively. Number of secondary branches/plant ranged from 1.33 to 8.47. Genotype G8, genotype G16, and G19 showed the highest (8.47) and the lowest (1.33) number of secondary branches/plant, respectively. Number of siliquae/plant ranged from 68.33 to 228.00 . The highest was recorded in the genotype G3 (228.00) and the lowest was in G16 (68.33). Length of siliquae ranged from 4.34 to $6.93 \mathrm{~cm}$. The highest was observed in genotype G15 (6.93 $\mathrm{cm})$ and the lowest was in G14 $(4.34 \mathrm{~cm})$. Days to 80\% maturity ranged from 86.33 to 97.33 . Genotype G8 showed the lowest (86.33) and genotype G1 was the highest (97.33) days to maturity. Number of seeds/siliquae ranged from 12.30 to 24.33. Genotype G21 showed the highest (24.33) number of seeds/siliquae and genotype G14 was the lowest (12.30). Thousand seed weight ranged from 3.11 to 4.50 g. Genotype G19 was the highest (4.50g) and genotype G25 was the lowest (3.11g). The highest (9.87g) seed yield/plant was recorded in Genotype G15 and the lowest (5.23g) was recorded in G5 (Table 1).

The highest co-efficient of variation (CV\%) was recorded in the character number of secondary branches/plant (53.77) followed by number of siliquae/plant (27.11), and 1000-seed weight (20.61g). Minimum variation was observed in the character days to $80 \%$ maturity (1.36) (Table 1). Considering the plant height, number of secondary branches/plant, siliquae/plant, maturity duration, seed yield and other yield contributing characters, the genotypes G8, G3, G17, G19, G10, G15, and G21 were selected for future breeding programme. 
Table 1. Mean Range and CV (\%) of seed yield and yield contributing characters of 32 genotypes of Brassica rapa.

\begin{tabular}{l|c|c|c|c|c}
\hline Characters & MS & Mean & Range & CV (\%) & SE \\
\hline DTF & 5.58 & 32.30 & $30.33-36.00$ & 4.02 & 0.18 \\
PHT & 275.83 & 96.89 & $74.33-118.33$ & 7.22 & 1.14 \\
NPB & 4.2 & 6.13 & $4.20-9.40$ & 18.24 & 0.15 \\
NSB & 12.67 & 4.83 & $1.33-8.47$ & $\mathbf{5 3 . 7 7}$ & 0.31 \\
NSP & 4599.79 & 153.28 & $68.33-228.00$ & $\mathbf{2 7 . 1 1}$ & 5.26 \\
PLH & 0.68 & 5.51 & $4.34-6.93$ & 8.16 & 0.06 \\
DEF & 19.94 & 90.50 & $86.33-97.33$ & $\mathbf{1 . 3 6}$ & 0.28 \\
SPS & 18.66 & 16.61 & $12.30-24.33$ & 15.66 & 0.34 \\
TSW & $0.39 \mathrm{~ns}$ & 3.57 & $3.03-4.50$ & 20.61 & 0.07 \\
YPP & 4.95 & 7.61 & $5.23-9.67$ & 20.42 & 0.19 \\
\hline
\end{tabular}

DTF $=$ Days to $50 \%$ flowering, $\mathrm{PHT}=$ Plant height $(\mathrm{cm}), \mathrm{NPB}=$ No. of primary branches/plant, NSB = No. of secondary branches/plant, NSP = No. of siliquae/plant, PLH = Length of siliquae $(\mathrm{cm})$, DEF $=$ Days to $80 \%$ maturity, SPS $=$ No. of seeds/siliquae, TSW $=1000$ seed weight $(\mathrm{g})$ and $\mathrm{YPP}=$ Seed yield per plant $(\mathrm{g})$, ns= Not significant.

\section{Variability among the genotypes}

Out of 32 genotypes the lowest days to flowering was taken by SAU Sharisa-1 S2 (30 days) and F6 $\times$ BARI Sharisa-9 P1 followed by BARI Sharisa-9 $\times$ BARI Sharisa-6 P3, SAU sarisha-1 S3, BARI Sharisa-9 $\times$ F6 P3 (31 days). The highest days to flowering was taken by BARI Sharisa-9 $\times$ BARI Sharisa-6 P1 (36.00 days) which was close to F6 $\times$ BARI Sharisa-9 P2 (35.00 days) (Table 2). The phenotypic and genotypic variances for this trait were 1.30 and 1.68, respectively. The phenotypic variances appeared to be little bit higher than the genotypic variance suggesting considerable influence of environment on the expression of the genes controlling this trait (Table 3).

The highest plant height was observed in SAU Sharisa-1 S2 $(118.33 \mathrm{~cm})$ followed by that of F6 $\times$ BARI Sharisa-9 $(117.67 \mathrm{~cm})$ and SAU Sharisa-1 S1 $(112.67 \mathrm{~cm})$, where as the lowest plant height was observed in BARI Sharisa-9 $\times$ BARI Sharisa-6 P5 $(74.33 \mathrm{~cm})$ (Table 2). Plant height showed phenotypic variance (75.63) and genotypic variance (48.95) with relatively high difference between them which indicated large genetic influences on this trait (Table 3).

Among 32 genotypes, the highest number of primary branches/plant was observed in F6 $\times$ BARI Sharisa 9 (9.40), where as the lowest was in BARI Sharisa-9 $\times$ BARI Sharisa-6 P5 (4.20). The number of primary branches/plant in 
SAU Sharisa-1 S1, SAU Sharisa-1 S2, BARI Sharisa- $6 \times$ R.Tori 7 S4 BARI Sharisa-6 $\times$ Tori 7) and Tori $7 \times$ F6 P1 were observed 9.00, 8.47, 7.13, 7.13, 10, and 7.03, respectively (Table 2). Number of primary branches/plant showed low differences between phenotypic variance (1.25) and genotypic variance (0.98) indicating the higher environmental influence on this character (Table 3).

The highest number of secondary branches/plant was observed in SAU Sharisa-1 S3 (8.47) followed by that of BARI Sharisa-6 $\times$ R.Tori 7 S4 (8.03) and Tori $7 \times$ F6 P1 (8.00), where as the lowest was observed in SAU Sharisa-1 S2 and BINA Sharisa-6 (1.33) (Table 2). Number of secondary branches/plant showed low difference between phenotypic variance (6.74) and genotypic variance (1.91) indicating high environmental influence on this trait (Table 3).

In the present experiment, the highest variation was found for number of siliquae/plant. The highest number of siliquae/plant was observed in BARI Sharisa-6 $\times$ Tori 7 (228.00), whereas the lowest was observed in BINA Sharisa-6 (68.33). The number of siliquae/plant of BARI Sharisa-9 $\times$ BARI Sharisa-6 P1, BARI Sharisa- $6 \times$ R.Tori 7, F6 $\times$ BARI Sharisa-9 and Tori 7× F6 P2 were $216.00,215.00 .00,214.00$, and 200.00, respectively (Table 2). The highest phenotypic variance (17.28) and genotypic variance (9.57) was observed for number of siliquae/plant with large environmental influence (Table 3).

The highest siliquae length was observed in SAU Sharisa-1 S1 $(6.93 \mathrm{~cm})$ followed by BARI Sharisa-9 × BARI Sharisa-6 P6 (6.33cm), F6 × BARI Sharisa$9 \mathrm{P} 2(6.18 \mathrm{~cm})$, and SAU Sharisa $1 \mathrm{~S} 3(6.03 \mathrm{~cm})$, whereas the lowest was observed in BARI Sharisa-9 × F6 P6 $(4.34 \mathrm{~cm})$ (Table 2). Length of siliquae showed minimum difference between phenotypic variance (0.16) and genotypic variance (0.02) indicating that they were less responsive to environmental factors for phenotypic expression (Table 3). The lowest days to maturity was taken by SAU Sharisa-1 S3 (86.33 days) followed by SAU Sharisa-1 S2 (87.67 days).

The highest days to maturity was taken by BARI Sharisa- $9 \times$ BARI Sharisa- 6 P1 (97.33 days) followed by F6 $\times$ BARI Sharisa-9 P2 (95.00 days) and BARI Sharisa-9 $\times$ BARI Sharisa-6 P7 (96.33 days) (Table 2). The phenotypic and genotypic variance for days to maturity was observed 6.14 and 1.52, respectively (Table 3) which indicated that the trait expression is highly controlled by genetic parameters.

The highest number of seeds/siliquae was observed in BINA Sharisa-6 (24.33) followed by SAU Sharisa-1 S1 (21.67) and SAU Sharisa-1 S2 (19.67), whereas the lowest was observed in BARI Sharisa-9 × F6 P6 (12.30) (Table 2). The phenotypic variances and genotypic variances for this trait were 6.77 and 3.96, respectively (Table 3). 
Table 2. Mean performances of 32 genotypes of Brassica rapa.

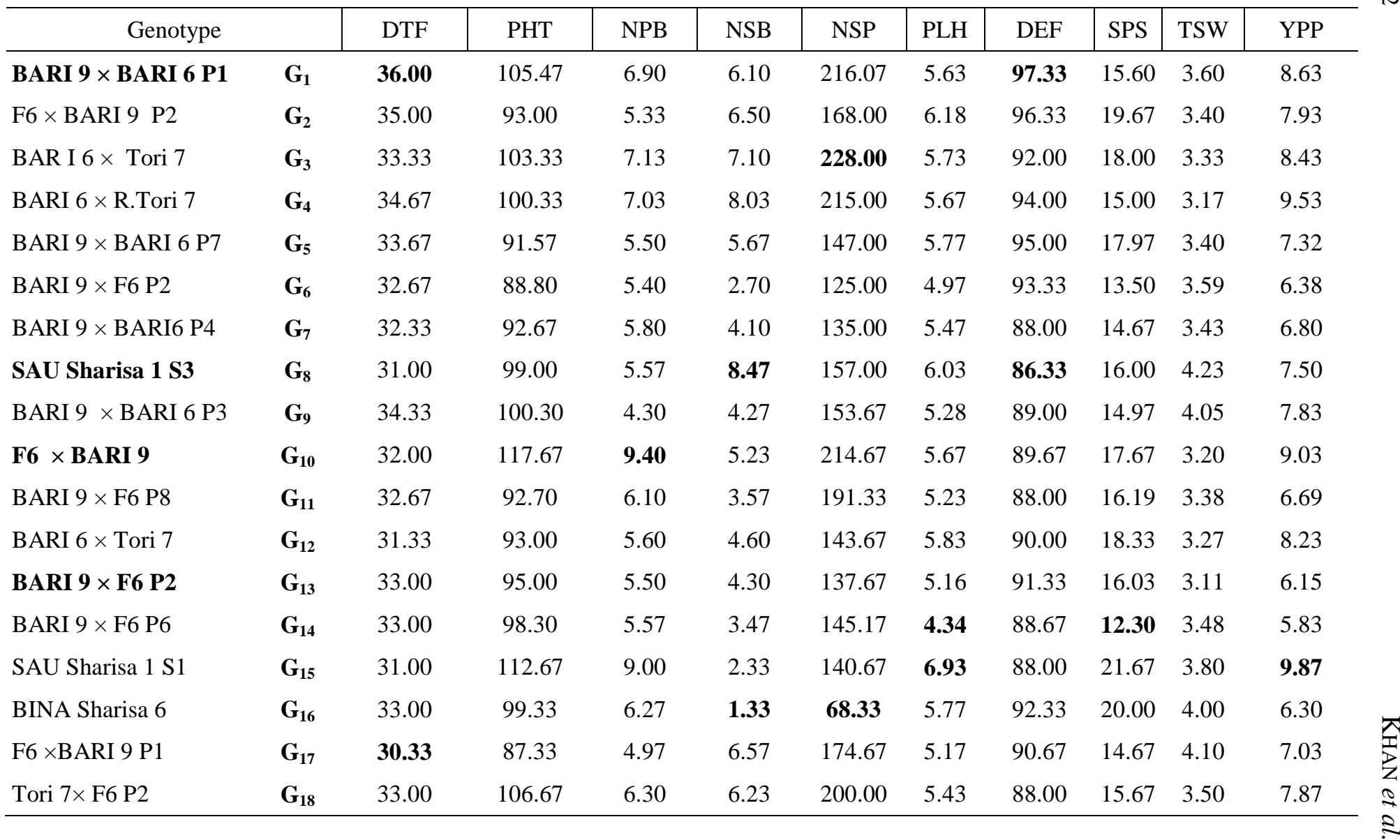


Table 2. Cont'd.

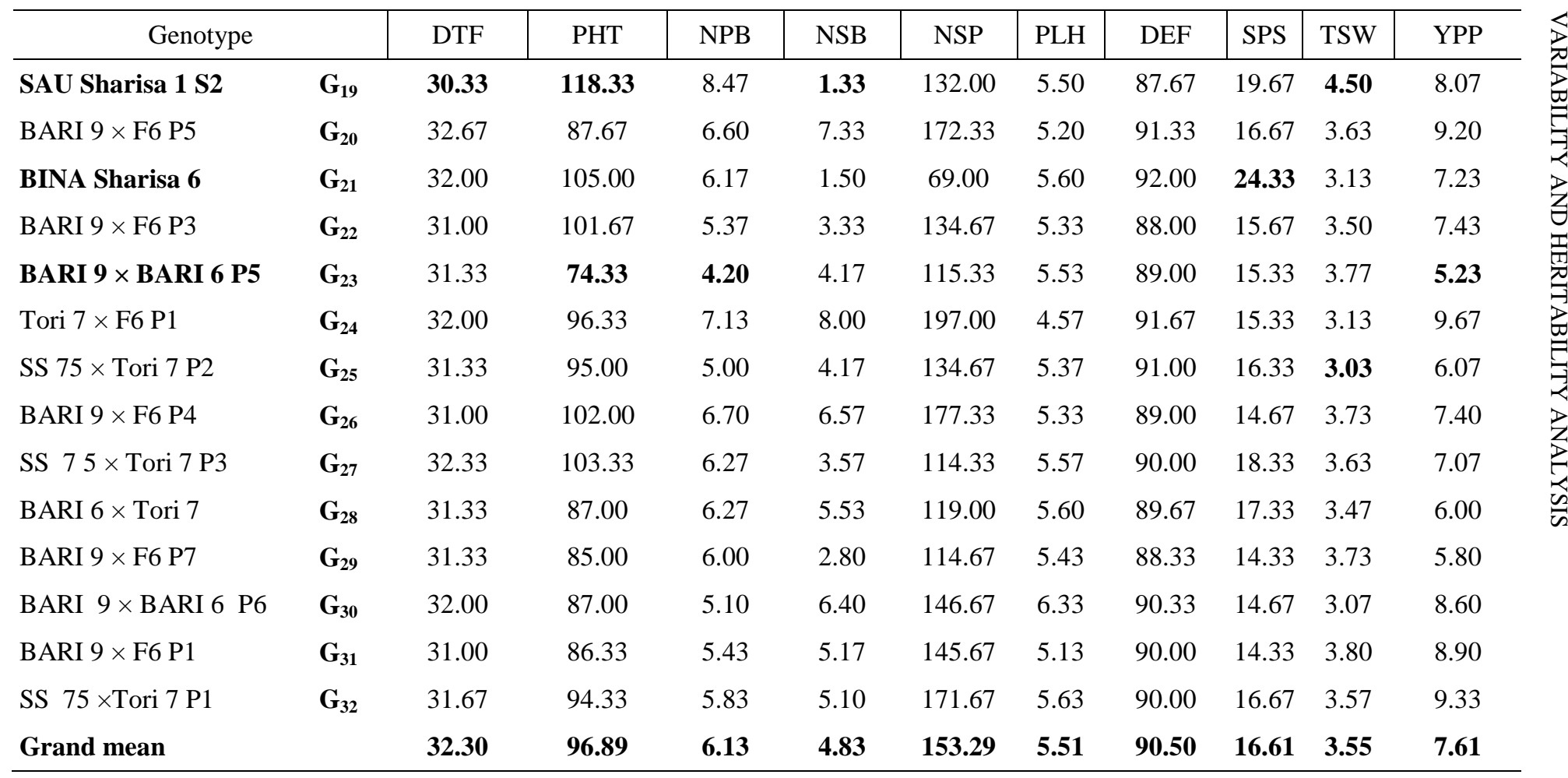

DTF $=$ Days to $50 \%$ flowering, PHT= Plant height $(\mathrm{cm})$, NPB $=$ No. of primary branches/plant, NSB = No. of secondary branches/plant, NSP $=$ No. of siliquae per plant, PLH = Length of siliquae $(\mathrm{cm})$, DEF $=$ Days to $80 \%$ maturity, SPS = No. of seeds per siliquae, TSW $=$ 1000 seed weight $(\mathrm{g})$ and YPP $=$ Seed yield per plant $(\mathrm{g})$. 
Thousand seed weight was found maximum in SAU Sharisa 1 S2 (4.50 g), followed by SAU Sharisa $1 \mathrm{~S} 3$ (4.23 g), whereas the minimum was found in SS $75 \times$ Tori 7 P2 (3.03 g) (Table 2). The phenotypic and genotypic variances for this trait were 0.43 and 0.02 , respectively (Table 3).

The highest amount of yield per plant was observed in SAU Sharisa-1 S1 $(9.87 \mathrm{~g})$ followed by that of Tori $7 \times$ F6 P1 (9.67 g), BARI Sharisa- $6 \times$ R. Tori 7 S4 (9.53 g), and SS $75 \times$ Tori 7 P1 (9.33 g), whereas the minimum yield per plant was observed in BARI Sharisa-9 × BARI Sharisa-6 P5 (5.23g) (Table 2). The phenotypic variance and genotypic variance were 2.42 and 0.83 , respectively (Table 3).

Table 3. Estimation of some genetic parameters in 32 genotypes of Brassica rapa.

\begin{tabular}{l|c|c|c|c|c|c|c}
\hline Characters & $\begin{array}{c}\text { Genotypic } \\
\text { variance }\end{array}$ & $\begin{array}{c}\text { Phenotypic } \\
\text { Variance }\end{array}$ & GCV & PCV & $\begin{array}{c}\text { Heritability } \\
(\%)\end{array}$ & $\begin{array}{c}\text { Genetic } \\
\text { Advance } \\
(1 \%)\end{array}$ & $\begin{array}{c}\text { Genetic } \\
\text { Advance } \\
\text { in Mean } \\
(1 \%)\end{array}$ \\
\hline DTF & 1.30 & 1.68 & 3.53 & 5.34 & 43.56 & 1.99 & 6.15 \\
PHT & 48.95 & 75.63 & 8.98 & 11.52 & 60.17 & 17.89 & 18.46 \\
NPB & 0.98 & 1.25 & 16.16 & 24.37 & 43.98 & 1.74 & 28.30 \\
NSB & 1.91 & 6.74 & 28.60 & 60.97 & 22.05 & 1.71 & 35.46 \\
NSP & 9.57 & 17.28 & 20.19 & 33.81 & 35.65 & 48.78 & 31.82 \\
PLH & 0.02 & 0.16 & 7.26 & 10.92 & 44.22 & 0.70 & 12.75 \\
DEF & 1.52 & 6.14 & 2.74 & 3.06 & 80.11 & 5.85 & 6.47 \\
SPS & 3.96 & 6.77 & 11.98 & 19.72 & 36.92 & 3.19 & 19.22 \\
TSW & 0.02 & 0.43 & 3.67 & 18.09 & 84.23 & 0.07 & 1.97 \\
YPP & 0.83 & 2.42 & 11.95 & 23.86 & 25.48 & 1.21 & 15.93 \\
\hline
\end{tabular}

DTF $=$ Days to $50 \%$ flowering, $\mathrm{PHT}=$ Plant height $(\mathrm{cm}), \mathrm{NPB}=$ No. of primary branches/plant, NSB $=$ No. of secondary branches/plant, NSP $=$ No. of siliquae/plant, PLH $=$ Length of siliquae $(\mathrm{cm})$, DEF $=$ Days to $80 \%$ maturity, SPS $=$ No. of seeds/siliquae, TSW $=1000$ seed weight $(\mathrm{g})$ and YPP $=$ Seed yield per plant $(\mathrm{g})$. GCV $=$ Genotypic co-efficient of variation, PCV= phenotypic co-efficient of variation.

The analysis of variance showed significant differences among the genotypes for all the characters. The ranges were high for most of the traits also. In order to obtain a clear understanding of the pattern of variations, the phenotypic variances were partitioned into genotypic and environmental variances. The highest genotypic, environmental, and phenotypic variances were found in plant height. The lowest variances were found in length of siliquae followed by 1000-seed weight. The phenotypic co-efficient of variations (PCV) were higher than the genotypic co-efficient of variations (GCV) for all the characters studied indicating the presence of environmental influence in the phenotypic expression of the characters. The difference between PCV and GCV was remarkably low for days to flowering. The difference between PCV and GCV was high for number of secondary branches/plant (Table 3). 


\section{Heritability and genetic advance}

The knowledge of heritability of a character helps the breeder in predicting the behaviour of the succeeding generation and making desirable selections. Days to $50 \%$ flowering exhibited intermediate heritability (43.56\%) with low genetic advance (6.15\%) (Table 3). As a whole, the low heritability and the consequent low genetic advance indicated the lower possibility of selecting genotypes. This results support the reports of Malik et al. (1995).

Days to maturity exhibited high heritability (80.11\%) with low genetic advance (6.47\%) which revealed higher possibility of selecting genotypes that would mature earlier. In some of the crosses the frequency of the segregating plants showing reduced maturity was comparatively high than the other crosses.

Plant height showed medium heritability (60.17\%) with good genetic advance (18.46\%) (Table 3). The medium heritability and the consequent intermediate genetic advance indicated the higher possibility of selecting genotypes. Varshney et al. (1986) found high heritability for plant height.

Number of primary branches/plant exhibited low heritability $43.98 \%$ with high genetic advance (28.30\%). As a whole, the low heritability and the consequent low genetic advance indicated the lower possibility of selecting genotypes. Number of secondary branches/plant exhibited low heritability $22.05 \%$ with low genetic advance (35.46\%). The low heritability and the consequent low genetic advance indicated the lower possibility of selecting genotypes. Katiyar and Singh (1974) reported low heritability for this trait.

Number of siliquae/plant exhibited low heritability (35.65\%) with low genetic advance (31.82\%). The low heritability and the consequent low genetic advance indicated the lower possibility of selecting genotypes for this character. This result supports the report of Paul et al. (1976).

Thousand seed weight showed high heritability (84.23) with low genetic advance $(0.07 \%)$. These results revealed the possibility of predominance of both additive and non-additive gene action in the inheritance of this trait. Kwon et al. (1989) and Rao (1977) reported high heritability for this trait. Yadava et al. (1982), Sharma (1984) and Kakroo and Kumar (1991) reported low to medium heritability for this trait. Number of seeds/siliquae showed low heritability (36.92\%). Malik et al. (1995) reported high heritability $\left(\mathrm{h}_{\mathrm{b}}^{2}>90 \%\right)$ for this trait.

1000-seed weight exhibited high heritability (84.23\%) with low genetic advance (1.97\%). This trait is governed by non-additive genes. Liang and Walter (1968) reported that moderate values of heritability and low genetic advance may be due to non-additive gene action which includes dominance and epistasis. Johnson et al. (1955) reported that heritability estimates along with genetic gain were more useful in prediction selection of the best individual. Seed yield/plant 
showed low heritability (25.48\%) with low genetic advance (15.93\%). These results support the reports of Liang and Walter (1968), but Singh et al. (1987) found high heritability for this trait.

Genotypic co-efficient of variation together with high heritability and genetic advance are considered as good estimates of genetic gain to be expected in making selection of superior genotypes on the basis of phenotypic performance. Johnson et al. (1955) mentioned that high heritability along with high genetic gain are more successful than the heritability alone to select desirable genotypes with higher yield. Panse (1957) stated that high value of heritability with low genetic advance indicated that the heritability was probably due to the effect of non-additive gene action. The characters with high values of GCV, PCV, and heritability accompanied by high genetic advance in percent of mean might be transmitted to their progenies and therefore, phenotypic selection based on these characters would be effective.

High GCV and PCV values were observed for number of secondary branches/plant. High heritability values along with low genetic advance in percentage of mean were obtained for 1000-seed weight, number of secondary branches/plant, seeds/siliquae, and siliquae length. Considering variability among the genotypes, heritability, genetic advance, percent co-efficient of variance, and field performances, the genotypes G-15, G-19, G-1, G-3, G-4, G-10, G-18, G21, and G-24 were found suitable for future breeding programme.

\section{References}

Allard, R. W. 1960. Principles of Plant Breeding. John Willey and Sons. Inc. New York.

Behl, R. K., B. D. Chowdhury, R. P. Shing and D. P. Shing. 1992. Morphophysiological determinants of oil yield in Brassica juncea under dry land conditions. Indian $J$. Genet. Pl. Breed. 52 (3): 280-284.

Burton, G. W. 1952. Quantitative inheritance in grasses. Proc. $6^{\text {th }}$ int. Grassland Cong.1 :227-83.

Falconer, D. S. 1989. Introduction to Quantitative Genetics. $2^{\text {nd }}$ Ed. English Language Book Society/Longman. 288.

Johnson, H. W., H. F. Robinson and R. F. Comstock. 1955. Estimates of genetic and environmental variability in soyabean. Agron. J. 47: 314-18.

Kakroo, P. and S. Kumar. 1991. Genetic determination of seed yield through it's components in Indian mustard. Indian J. Genet. Pl. Breed. 51(2): 82.

Katiyar, A. P. and B. D. Singh. 1974. Interrelationship among yield and its components in Indian mustard. Indian .J. Agric. Sci. 44: 287-290.

Khaleque, M. A. 1985. A Guide Book on Production of Oil Crops in Bangladesh. DAE and FAO/UNDP project BGA/79/034, Strengthening the Agricultural Extension Service Khamarbari, Farmgate, Dhaka. 
Kwon, B. S., J. I. Lee and Y. A. Chae. 1989. Genetic studies on some agronomic characters in rapeseed. Korean J. Pl. Breed. 21(1): 22-27.

Liang, G. H. L. and T. L. Walter. 1968. Heritability estimates and gene action effect for agronomic traits in grain sorghum. Crop. Sci. 8(1): 77-88.

Malik, V., H. Singh and D. Singh. 1995. Gene action of seed yield and other desirable characters in rapeseed. Analysis Biol. (Ludhiana). 11(1/2): 94-97.

Panse, V. G 1957. Genetic of quantitative characters in relation to plant Breeding. Indian J. Genet. 17: 318-328.

Paul, N. K., O. I. Joarder and A. M. Younus. 1976. Genotypic and phenotypic variability and correlation studies in Brassica juncea L. Zeeitcchrift fur plffazenzuchtung 77(2): 145-154.

Rao, T. S. 1977. Genetics of yield components in brown sarson. Genetica Iberica. 29(3/4): 219-227.

Rahman, L. 1981. Oil seed Research \& Development Ativities at BAU. Proc. of the workshop on Oil Crop Improvement, BARI. Oilseed Research Project. Ed. By Khuleque M.A., A.B.M. Abdul Khair, Md. Ali Akber \& Md. Moszammal Haque.

Sharma, S. K. 1984. Variation and correlation studies in Indian mustard (B. juncea). Indian J. Agril. Sci. 54(2): 146-147.

Singh, R. P., B. P. S. Malik. and D. P. Singh. 1987. Variation for morphological characters in genotypes of Indian mustard. Indian J. Agril. Sci. 57(4): 225-230.

Singh, R. K. and B. D. Chaudary. 1985. Biometrical Methods in Quantitative Genetic Analysis. Kalyani Publishers, New Delhi, India.: 56.

Varshney, S. K., B. Rai and B. Singh. 1986. Component analysis of harvest index in Brassica oilseeds. Indian J. Agril. Res. 20(3): 129-134.

Yadava, T. P., P. Kumar. and S. K. Thakral. 1882. Association of pod yield with some characters in groundnut. Hariana Agril. Univ. J. Res. 14(1): 75-88. 